\title{
MATERIALS FOR STRENGTHENING OF GAS TURBINE BLADES
}

\author{
A.M. KOSTIN ${ }^{1}$, A.Yu. BUTENKO ${ }^{1}$ and V.V. KVASNITSKY ${ }^{2}$ \\ ${ }^{1}$ Adm. S.O. Makarov National Shipbuilding University \\ 9 Geroev Stalingrada Ave., 54025, Nikolaev, Ukraine. E-mail: kostin.weld@gmail.com \\ ${ }^{2}$ NTTU «Kiev Polytechnic Institute» \\ 6/2 Dashavskaya Str., 03056, Kiev, Ukraine
}

\begin{abstract}
The advantages and disadvantages of existing technologies for strengthening the contact surfaces of working blades of gas turbines applying cast rods of stellite, nickel alloy KBNKhL-2 and plates of alloy KhTN-61 were studied. The necessity of development of new wear-resistant material for strengthening the shroud platforms of working blades was grounded. Two pilot alloys on the cobalt base of $\mathrm{Co}-\mathrm{Si}-\mathrm{B}$ and $\mathrm{Co}^{-} \mathrm{Si}-$ $\mathrm{B}-\mathrm{Cr}_{3} \mathrm{C}_{2}$ systems were investigated. The high temperature wear resistance of materials was evaluated. 3 Tables, 1 Figure.
\end{abstract}

Keywords: surfacing, blades of gas turbines, strengthening technology, stellite, nickel alloy, cobaltbased alloy, high temperature wear resistance

At the present day the main problem in production of working blades of modern gas turbine engines (GTE) is providing their high wear and heat resistance, which would provide the required characteristics of contact surfaces of the working blades in the whole temperature range of their operation.

In the work the working blades are considered, manufactured of cast nickel alloys of the type ChS88U-VI, the operation characteristics of which are not high, therefore, there is necessity in strengthening the contact surfaces (shroud platforms) of working blades using materials corresponding to the criteria of engines operation.

At the enterprises manufacturing GTE, to provide the contact surfaces of working blades with the necessary properties, in particular, hot hardness and wear resistance, different compositions and methods of strengthening are applied. For example, the method of manual argon arc surfacing using cast rods of Co-based stellite of grade Pr-V3K-r of 2-3 mm diameter is well-known. This stellite is characterized by high hardness, wear and corrosion resistance. However the considered technology has a number of significant disadvantages:

- alloys ChS88U-VI, ChS70U-VI and ChS104-VI have a poor weldability, and in this connection in electric arc surfacing the cracks are formed transferred to base metal. Stellite $\mathrm{Pr}$ V3K-r and the given nickel alloys have different coefficients of linear thermal expansion, that re-

(c) A.M. KOSTIN, A.Yu. BUTENKO and V.V. KVASNITSKY, 2014 sults in appearance of the complex fields of natural stresses during cooling of a deposited part;

- surfacing of parts is performed in two passes to provide the required hardness, as far as in argon arc surfacing the intensive stirring of stellite with the base metal occurs, as a result of which the hardness of the first layer does not exceed $H R C$ 32-35. The surfacing in two passes results in excessive consumption of expensive stellite and increase in labor intensiveness of the manufacture.

It is possible to perform strengthening of shroud platforms of GTE working blades using oxy-acetylene surfacing by nickel alloy KBNKhL-2. In this case a high quality of deposited metal without any outer and inner defects with the stable hardness $H R C 60$ over the whole area of end or shroud platform of working blade is provided.

The significant disadvantage of application of alloy KBNKhL-2 is the fact that during overheat temperature of engine operation the fusion of contact surfaces frequently occurs, that further results in coming of engine out of order in general.

The problem of heat and wear resistance of shroud platforms can be solved, for example, by application of brazing-on of plates of Co-based alloy KhTN-61, the operation of which is possible at the temperatures of up to $1100{ }^{\circ} \mathrm{C}$. However, brazing is not an acceptable method for strengthening blades of intricate configuration.

Therefore, the analysis of properties, efficient working temperatures of operation and possible methods of deposition of wear-resistant materials shows that none of the existing industrial wearresistant materials meets the technical requirements as to the technological process of strength- 
ening of contact surfaces of GTE parts considered in this work. Therefore, the development of new heat- and wear-resistant material for strengthening of shroud platforms is required, which could provide the preset conditions of their operation.

To the main criteria of development of new wear-resistant material for strengthening of contact surfaces of blades the following can be referred: high heat resistance, hardness of not less than $H R C 40$ at increased operation temperatures, and high temperature wear resistance.

Besides, the main technological criterion in development of new strengthening material is its melting temperature, which should not exceed $1220 \pm 10{ }^{\circ} \mathrm{C}$. Otherwise it will be impossible to avoid softening of base metal and formation of cracks in the transition zone.

To conduct investigations the authors offered two pilot compositions on the base of cobalt of $\mathrm{Co}-\mathrm{Si}-\mathrm{B}(\mathrm{No} .1)$ and $\mathrm{Co}-\mathrm{Si}-\mathrm{B}-\mathrm{Cr}_{3} \mathrm{C}_{2}$ (No.2) systems. Microstructure of surfacing by oxy-acetylen flame using pilot compositions is shown in the Figure.

One of the important characteristics of strengthening material is the hardness of deposited layer. The authors determined hardness of strengthening compositions after heat treatment and thermal cycling. The mode of heat treatment of the specimens is given in Table 1. The mode of thermal cycling of pilot specimens was as follows: starting and end temperature is 20 and $1100{ }^{\circ} \mathrm{C}$, respectively, and number of cycles is 15-20. The measurement results of hardness are given in Table 2. The analysis of results shows that the hardness of pilot materials meets the operation requirements.

Determination of wear resistance was carried out in the installation providing operation conditions of GTE blades maximum close to the real ones. In the process of tests the specimens were under the conditions of dynamic collisions at increased temperatures of operating environment. At the same time pilot specimens of base metal

Table 1. Mode of heat treatment of pilot specimens

\begin{tabular}{||l|c|c||}
\hline \multicolumn{1}{|c|}{ Succession of performance } & $\begin{array}{c}\text { Temperature, } \\
{ }^{\circ} \mathrm{C}\end{array}$ & $\begin{array}{c}\text { Exposure } \\
\text { time, } \mathrm{h}\end{array}$ \\
\hline Annealing & 1020 & 2 \\
\hline Cobalting & $970 \pm 10$ & 6 \\
\hline Aluminizing & $970 \pm 10$ & 6 \\
\hline Diffusion annealing in vacuum & $1030 \pm 10$ & 2 \\
\hline Recrystallization annealing & $1030 \pm 10$ & 2 \\
\hline Vacuum annealing & $1030 \pm 10$ & 2 \\
\hline Ageing & $850 \pm 10$ & $16-17$ \\
\hline
\end{tabular}

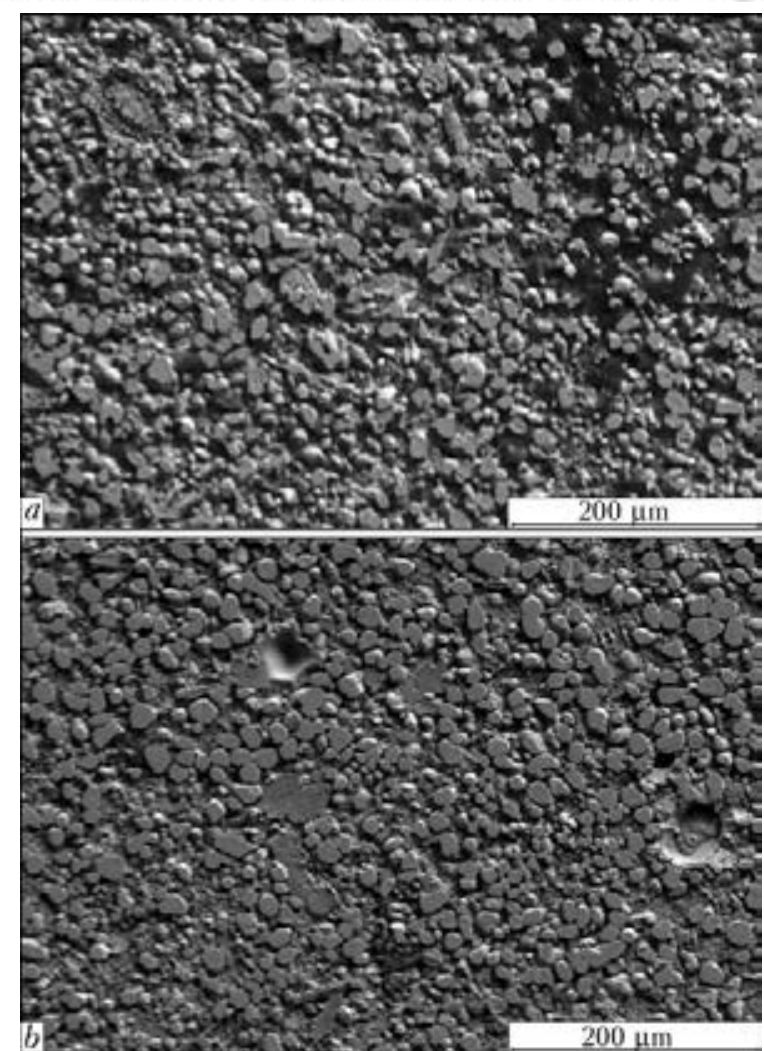

Microstructure of deposited layer of strengthening composition $1(a)$ and $2(b)$

ChS88U-VI and specimens deposited using stellite Kh30N50Yu5T2, which nowadays is the maximum efficient for strengthening of working blades, were tested.

The conditions for tests were as follows: temperature of about $1150{ }^{\circ} \mathrm{C}$, initial load of $50 \mathrm{MPa}$, amplitude of mutual displacement of $0.169 \mathrm{~mm}$, test period of $2 \mathrm{~h}$. The influence of temperature on wear resistance of specimens was evaluated according to the test results in the environment of combustion products of aircraft fuel of the «kerosene» type. To carry out tests the aircraft kerosene of grade TS-1 was applied.

To eliminate the possible influence of test temperature on physical and mechanical properties of the investigated materials and the next results of evaluation of wear resistance, the tests of specimens were carried out at the contact of only one investigated side.

The wear resistance of pilot materials was evaluated according to the wear intensity

Table 2. Results of measurements of hardness of strengthening compositions

\begin{tabular}{|c|c|c||}
\hline Alloy & $\begin{array}{c}\text { Hardness after heat } \\
\text { treatment } H V 10\end{array}$ & $\begin{array}{c}\text { Hardness after thermal } \\
\text { cycling } H V 10\end{array}$ \\
\hline No.1 & 752 & 572 \\
\hline No.2 & $606-690$ & 525 \\
\hline
\end{tabular}


Table 3. Results of measurements of wear intensity of pilot alloys

\begin{tabular}{|c|c|c||}
\hline Alloy & Test time, min & $\begin{array}{c}\text { Average intensity of } \\
\text { wear } J_{\mathrm{V}^{1}} 10^{-6}, \\
\mathrm{~mm}^{3} / \text { cycle }^{6}\end{array}$ \\
\hline ChS88U-VI & 120 & 2.379 \\
\hline Kh30N50Yu5T2 & 60 & 10.126 \\
\hline No.1 & 120 & 2.761 \\
\hline No.2 & 120 & 2.372 \\
\hline
\end{tabular}

$$
J_{\mathrm{V}}=V / N,
$$

where $J_{\mathrm{V}}$ is the volumetric wear intensity, $\mathrm{mm}^{3}$ / cycle; $V$ is the volume of worn-out material (determined according to the profilogram of worn-out specimens), $\mathrm{mm}^{3} ; N$ is the number of load cycles (corresponds to the frequency of oscillations of specimens).

The test results of high temperature wear resistance are given in Table 3 .

The analysis of test results showed that alloy Kh30N50Yu5T2 can not resist the given dynamic and temperature loads. At the contact surface a great number of scale, spallings, cracks, tears and overlaps are observed, that evidence of fracture of strengthening deposition layer. ChS88U-
VI alloy and pilot alloys 1 and 2 show almost the same resistance to high temperature wear.

Thus, in general, the analysis of test results showed that at $T_{\text {test }} \approx 1150{ }^{\circ} \mathrm{C}$, which is close to the temperature of $\gamma^{\prime}$-phase dissolution, the volumetric content and morphology of strengthening disperse phase does not play a decisive role in providing high wear resistance of strengthening compositions. In this case the properties of solid solution base of alloy are of particular importance.

Under the real operation conditions of GTE the particular importance is given not only to serviceability of wear-resistant materials at extra-limiting temperature loads, which make up the minimum percent from the total time of engine operation, but also to wear resistance of alloys during the start $\left(\approx 20{ }^{\circ} \mathrm{C}\right)$ and especially at operation temperatures $\left(\approx 900{ }^{\circ} \mathrm{C}\right)$. Besides, it is known that cobalt alloys demonstrate considerable decrease in wear resistance at the temperatures of about $500{ }^{\circ} \mathrm{C}$, that requires the detailed investigations in the whole operation temperature range from 20 to $1150{ }^{\circ} \mathrm{C}$.

Received 25.04.2014 